\title{
Intersecciones: cuerpos $y$ sexualidades en la encrucijada. Raquel (Lucas) Platero. Barcelona: Bellaterra, 2012. 328 pp.
}

Marisa Ruiz Trejo ${ }^{1}$

Universidad Autónoma de Madrid²

marisa.ruiz@uam.es

Becaria del Programa de Formación de Profesorado Universitario (FPU) del Ministerio de Educación y Ciencia de España.

2 Doctoranda en Antropología Social de la Universidad Autónoma de Madrid. 
En este libro, Raquel (Lucas) Platero coordina una antología que, bajo el título Intersecciones: cuerpos y sexualidades en la encrucijada, reúne diez textos de autores activistas e intelectuales que proponen la interseccionalidad y el análisis crítico queer como herramientas metodológicas para abordar las sexualidades no normativas. La peculiaridad de este abordaje es que está pensado como hilo conductor entre lo académico y el activismo.

En la primera parte encontramos dos textos clásicos sobre interseccionalidad de Kimbele Williams Crenshaw y el manifiesto feminista negro de Combahee River Collective. Un segundo apartado reúne varios textos originales de diversos autores: Paco Guzmán, Carmen Romero Bachiller, Javier Sáez, David Berná, Eva Herrero, Gerard Coll-Planas, Virginia Villaplana, Cécile Stephanie Stehrenberger y el propio Platero. Quienes escriben en este libro nos aproximan a la diversidad de $\operatorname{osos}^{3}$, a las identificaciones LGTB con diversidad funcional, presos y presas gays, transexuales e intersexuales, subjetividades migrantes LGTB en los Centros de Internamiento para Extranjeros, en la Sección Femenina, femmes y butches, gitanos gays, cero-positivos, etc.

Es un trabajo novedoso debido a que son escasos los estudios que abordan la cuestión de las sexualidades disidentes y expresiones de género no normativas entrelazadas con otras articulaciones. Las reflexiones que aporta sobre diferentes realidades históricamente negadas dan como resultado un libro atractivo por sus planteamientos y lleno de cuestionamientos a las relaciones de poder. De manera ágil, se muestran las formas de evidenciar los privilegios y una apuesta de consideración del sujeto desde la acción política. La propuesta de este libro no se queda en las formas académicas tradicionales sino que tiene en el entrecejo generar movilización social. Los autores no hablan simplemente como especialistas que objetivan las voces sino que lo hacen a través de expresiones de sí mismos mediante las cuales se representan y afirman sus agenciamientos politicos.

\section{La encrucijada de la interseccionalidad}

Desde la década de 1980 la interseccionalidad se popularizó en la academia norteamericana como término teórico conceptual que, entre varias cuestiones, muestra las diferentes formas en las que interactúan

\footnotetext{
3 Osos es la manera en que se conoce a los hombres gays con apariencia masculina hegemónica (fornidos, con vello facial) opuesta al estereotipo dominante de gay afeminado.
} 
la raza y el género en el caso de las mujeres negras en Estados Unidos. Cada artículo de este libro nos lleva a estudios que utilizan la metodología interseccional para mostrar cómo funcionan las opresiones en contextos muy diversos.

Platero, profesor e investigador de la Universidad Complutense de Madrid, nos muestra a través de las intersecciones cómo la sexualidad no habla desde una posición puramente académica sino que se sitúa en los cruces que atraviesan sus propias subjetividades reflexivas como parte de una familia con diversidad funcional, junto con una sexualidad no normativa y varias inflexiones de identidad de género en tránsito. Las formas de discriminación y desigualdad no son relacionadas simplemente para visibilizar a los grupos minoritarios sino más bien, para evidenciar los privilegios que favorecen ciertas subjetividades dominantes: la masculina blanca, urbana, heterosexual, sin diversidad funcional y con acento, así como el uso de una lengua hegemónica. Como se señala en la introducción del libro, no se trata tanto de contar cuántas discriminaciones atraviesan a un sujeto en forma de una lista inagotable de desigualdades, sino de analizar cómo las experiencias de una persona resultan de la interrelación de muchas estructuras socialmente construidas.

Este libro contribuye a llenar un vacío teórico y empírico en las reflexiones críticas sobre las sexualidades no normativas, sobre todo, aquellas relacionadas con la raza y la diversidad funcional, asi como con la cuestión de clase, las funciones lingüistica y cultural-elementos menos estudiados-, que aparecen en algunos de los artículos de esta compilación. Quedan abiertas algunas interrogantes que valdrá la pena abordar en futuras aproximaciones centradas en cómo las expresiones de la sexualidad y de la identidad sexual o de género se relacionan con la formación del mundo moderno-colonial en las jerarquías de poder global.

\section{Cómo citar este artículo}

Ruíz, M. (2015). Reseña del libro Intersecciones: cuerpos y sexualidades en la encrucijada, por R. L. Platero. Universitas Humanistica, 79, 257-259. http:// dx.doi.org/10.11144/Javeriana.UH79.icse 